\title{
The relationship of economic sentiment and GDP growth in Russia in light of the Covid-19 crisis
}

\author{
Liudmila Kitrar, Tamara Lipkind
}

\section{A B S T R A C T}

Objective: The objective of the article is to prove the empirical and predictive value of the aggregate opinions of businesses and households for expanding cyclical macroeconomic data in Russia, especially during the coronavirus shocks.

Research Design \& Methods: We use qualitative information from surveys that cover about 24000 organisations and 5100 households in all Russian regions. The total economic sentiment indicator (TESI) combines information on 18 survey-based indicators. Cross-correlation analysis, Hodrick-Prescott filtering, and a vector autoregressive (VAR) model with dummy variables are used as the research methods.

Findings: The study confirms an almost synchronous cyclic conformity of the gross domestic product (GDP) growth and TESI dynamics for the period of 1998-2020. Probable GDP growth until the end of 2021 is estimated based on the expected impulses in the TESI dynamics, including those due to the sudden impact of the coronavirus.

Implications \& Recommendations: Assessments of business and household activity are reliable and available much earlier than quantitative statistics on GDP growth. Therefore, we advise to use them as an early warning system about economic growth and take them into account in policymaking.

Contribution \& Value Added: We are the first to confirm the effectiveness and reliability of TESI as a leading indicator of GDP growth in Russia, using data from large-scale business surveys and with a focus on crisis shocks.

Article type: research article

Keywords: business and consumer surveys; economic sentiment indicator; composite indicators;

JEL codes: economic growth; GDP growth; growth cycles

$\mathrm{C} 81, \mathrm{C} 82, \mathrm{E} 32, \mathrm{O} 47$

Received: 22 September $2020 \quad$ Revised: 12 December 2020 Accepted: 15 December 2020
\end{abstract}

\section{Suggested citation:}

Kitrar, L., \& Lipkind, T. (2021). The relationship of economic sentiment and GDP growth in Russia in light of the Covid-19 crisis. Entrepreneurial Business and Economics Review, 9(1), 7-29. https://doi.org/10.15678/EBER.2021.090101

\section{INTRODUCTION}

During periods of cyclical reversals to a slowdown or acceleration of economic development, what complicates flash quantitative measurements of current and expected economic development are the growing uncertainty of economic business activity, new challenges for the economy and society, and risks of sudden changes compared to preliminary estimates.

To gain additional information about the possible prospect of the country achieving Sustainable Development Goals and to increase the effectiveness of statistical monitoring in the new economic situation, we advise focusing on information from businesses and households based on regular largescale surveys by the Federal State Statistics Service (Rosstat).

We studied the dynamics of GDP growth and the aggregate results of surveys among managers and consumers - i.e. the total economic sentiment indicator (TESI) - for the period of 1998-2020. The 
key question of the study was whether the quantified opinions of economic agents, combined in composite indicators, are relevant for the early estimation of macroeconomic development, especially with sudden short-term impulses in sectoral evolution.

Sharp changes for the worse in economic situation - which began in the first quarter of 2020 - will negatively affect further aggregate supply and demand until at least the end of 2021. These tendencies will become especially pronounced if uncertainty persists and new crises arise. For Russia, what is becoming more obvious is the prospect for overcoming negative sectoral developments according to the scenario of a W-shaped recovery of economic growth (IMF, 2020).

Therefore, as a special case for flash quarterly nowcasts of GDP growth, we examine the sharp negative shock in the dynamics of the composite survey indicator - caused by the coronavirus attack from Q2-2020 - in the context of a possible new cyclical reversal and subsequent recession.

We use a universal model specification for the case of two economic dynamics - the GDP growth and TESI - determined by the main goal of the study: to substantiate the empirical and predictive value of aggregated results of business and consumer surveys (BCS) for expanding current and expected short-term information about economic growth in Russia. Such information is useful for decision-makers and the expert community, especially during rapid negative changes.

There are two scientific novelties in this paper:

1. The introduction of a new composite indicator TESI into the practice of economic analysis; TESI aggregates quantified information on the sentiment of businesses and consumers in Russia based on the results of surveys conducted by the Federal State Statistic Service (Rosstat) in all Russian regions over 20 years.

2. The substantiation of the possibility of using accumulated TESI values in the short- and mediumterm forecasting of GDP growth, especially in the context of the ongoing Covid-19 crisis.

Important advantages of TESI are its significant correlation with reference dynamics: the quarterly GDP growth (as a year-on-year percentage) for the period from the Q1-1998 to the Q2-2020 and harmonisation with the composite index used by the European Commission (EC) to aggregate BCS results in European countries.

This paper is structured as follows. First, we provide a literature review on approaches to using survey-based indicators in economic analysis. Then, we describe the data and methodology used. Next, we develop the hypothesis about the compatibility of cyclical dynamics of aggregate economic sentiment and GDP growth. Later, we calculate scenario forecasts for GDP growth until the end of 2021 by using a VAR model with dummy variables. The concluding section discusses the main results and possible areas for future investigation.

\section{LITERATURE REVIEW}

Composite indicators of sentiment based on results of business and consumer surveys (BCS) are widely used in international practice for the early estimation of economic growth; e.g. the European Commission's harmonised confidence indicators, ${ }^{1}$ the Purchasing Managers' Index (PMI) by IHS Markit, ${ }^{2}$ and other indices calculated by various institutions. These indicators, obtained by aggregating individual measures that reflect the perceptions or expectations of respondents, evaluate multidimensional phenomena that are not covered by traditional statistics. Over the past decade, composite sentiment indicators are in high demand; they become official statistical short-term indicators and are used in various areas of economic analysis, including business cycles analysis, well-being measurements, sentiments, confidence and expectations of businesses and households, and international comparisons (UNECE, 2019).

In particular, the economic sentiment indicator (ESI) is widespread in European countries; the ESI is calculated and published monthly by the European Commission (EC) for European Union's (EU)

\footnotetext{
${ }^{1}$ The Directorate-General Financial and Economic Affairs of the European Commission, https://ec.europa.eu/info/businesseconomy-euro/indicators-statistics/economic-databases/business-and-consumer-surveys/download-business-and-consumer-survey-data/time-series_en.

2 IHS Markit, https://ihsmarkit.com/products/pmi-faq.html.
} 
Member States and the eurozone within the Joint Harmonised EU Programme of BCS. ${ }^{3}$ The economic rationale and the algorithm for ESI calculation are presented in the basic methodological recommendations by the EC's Directorate-General for Economic and Financial Affairs (DG ECFIN) (EC, 2020).

The ESI belongs to a group of coincident composite indicators of business activity, as it changes synchronously with the dynamics of reference statistic: the GDP growth. However, the ESI uses simple questionnaires and short data processing, and it is published much earlier than GDP, thus providing early signals of changes in economic activity. Timeliness and a high synchronous correlation with the reference statistic are the key ESI advantages (EC, 2020; Kitrar et al., 2015; Lipkind et al., 2019; UNECE, 2019).

A broad consensus has been reached regarding the coincident properties of BCS indicators; there is also evidence of their ability to predict the evolution of economic growth (Cesaroni, 2011). Recent studies investigate the performance of survey-based composite indicators - including the ESI - during recessions and crises at both European and country levels. Biau and D'Elia (2011) give evidence to a change in the relationship between the ESI and the GDP growth in European countries before and after the 2008 crisis and conclude that the further study of this relationship is necessary. A number of articles examine the possible change in correlations between quantitative (hard) statistics and qualitative (soft) survey-based indicators after the European Great Recession of 2008-2012 (EC, 2016; Gayer \& Marc, 2018). The studies confirm the hypothesis of a level shift or 'new modesty,' according to which survey indicators rose to values that did not correspond to the post-crisis levels of reference indicators (GDP growth, industrial production, etc.).

Nonetheless, BCS indicators remain an important tool in economic analysis and forecasting. European studies (EC, 2017) prove that the post-crisis ESI dynamic demonstrates an even higher correlation with annual GDP growth. Astolfi et al. (2016) confirm the leading nature of dated turning points based on OECD composite indicators compared to those based on national accounts during the Great Recession. Cesaroni and lezzi (2017) note the high statistical ability of survey-based indicators to predict macroeconomic changes in the short term.

Business trends and macroeconomic developments in recent years have renewed scholarly interest in the cumulative effects of time-varying uncertainty. Bloom (2014) examines the causes and consequences of fluctuations in uncertainty and concludes that external shocks leading to recessions directly increase uncertainty, but uncertainty increases endogenously during recessions. In international practice, soft statistics - the disagreement between the forecasts of survey respondents - are used as a proxy indicator of economic uncertainty (Bachmann et al., 2013).

Most studies devoted to the economic consequences of the Covid-19 pandemic are based on quantitative statistics: dynamics of GDP and the output of goods and services, volumes of imports and exports, industry indicators, changes in global value chains (Jorda et al., 2020; Gollier \& Straub, 2020; Fernandes, 2020; Bonadio et al., 2020; Guerrieri et al., 2020). Such statistics are usually published with a significant lag, although the need for flash estimates based on monitoring economic sentiments of businesses and consumers increases during periods of crisis.

The seminal papers on nowcasting economic growth (Angelini et al., 2008; Banbura \& Runstler, 2007) investigate the role of high frequency indicators, both quantitative and qualitative, and find that they provide useful information for predicting GDP. The empirical results of further studies show that adding flash BCS data to the set of indicators can improve nowcast and forecast accuracy (Darracq, Paries, \& Maurin, 2008; Drechsel \& Maurin, 2011; Girardi, 2014; Girardi et al., 2015).

Various econometric methods are applied to produce early estimates of economic growth using BCS indicators. Lehmann and Wohlrabe (2013) develop an autoregressive distributed lag (ADL) model with hard and soft statistics for forecasting GDP in German regions. D'Amato et al. (2015) exercise the nowcasting of Argentinian GDP growth by using bridge equations and the dynamic factor model (DFM) with consumer surveys data. DFM models, which include survey information, are also used to forecast GDP for the eurozone (Banbura \& Runstler, 2007; Basselier et al., 2017), along with France, Germany, Italy, Japan, the United Kingdom, and the United States of America (Ollivaud et al., 2016). Galli et al.

\footnotetext{
${ }^{3}$ The latest ESI releases can be found here: https://ec.europa.eu/info/business-economy-euro/indicators-statistics/economic-databases/business-and-consumer-surveys/latest-business-and-consumer-surveys_en.
} 
(2019) apply the DFM and mixed frequency data sampling (MIDAS) regression models to monitor short-term economic developments in Switzerland. The nowcasting performance of the MIDAS regression model for the eurozone GDP in a pseudo real-time setting is evaluated in an EC article (2018).

Vector autoregressive (VAR) models based on BCS data or combined hard and soft statistics are developed in Hansson et al. (2003), Mattos et al. (2016), and in articles by the EC (2014). The researchers conclude that VAR forecasting accuracy often outperforms the alternatives procedures including DFM.

In Russia, the empirical measurement of economic growth is not an easy task due to the lack of long-term time series, especially at the industry-disaggregated level. In addition, frequent revisions of data and weighting factors complicate statistical analysis and the interpretation of its results.

Most relevant Russian studies are devoted to the analysis of GDP dynamics, the dating of cyclical turning points, and the construction of leading indicators based on quantitative statistics. In particular, in Rayskaya et al. (2012), a conjuncture index consists of an extensive set of quantitative indicators of supply and demand. Dubovskiy et al. (2015) use national accounts statistics for this purpose. The decomposition of Russian GDP growth rates based on the Cobb-Douglas production function is developed in SinelnikovMurylev et al. (2015). Polbin (2020) estimates the trajectory of the growth rate of Russian GDP based on an autoregressive model with oil prices as a control exogenous variable for GDP dynamics. Smirnov (2020) provides an overview of leading indicators for Russia with an analysis of their advantages and disadvantages and the ability to give warnings about new phases of the economic cycle. However, as far as we know, there are no studies in the Russian academic literature that directly refer to the analysis of the longterm dynamics of the business activity of economic agents formed on the basis of large-scale Rosstat surveys and its correspondence to quantitative estimates of economic growth for a period of over 20 years.

To simulate the relationship between the GDP growth and the TESI, we chose relatively simple model specifications. Typically, such specifications consist of a minimum number of equations that reflect a single theoretical macroeconomic relationship, and they only operate with significant determinants of the modelled process. Therefore, we used an approach to modelling the cyclical relationship of indicators based on empirical facts about business cycles and vector autoregressions, initially allowing no more than seven to eight parameters of the standard VAR model (e.g. Bernanke et al., 2005; Kitrar et al., 2020).

Such model representations can differ significantly. For example, they can reflect the a priori assumed theoretical macroeconomic ratio (Korhonen \& Mehrotra, 2010; Mehrotra \& Ponomarenko, 2010). Korhonen and Mehrotra (2009) identify economic shocks based on a theory-driven identification scheme. In articles by Granville and Mallick (2010) and Mallick and Sousa (2013), sign restrictions are imposed on the response impulse functions. Rautava (2013) considers them as the most important determinants of the modelled process. A class of Bayesian VAR (BVAR) models is aimed at overcoming the 'curse of dimensionality.' Reducing the number of estimated parameters is conducted based on the researcher's a priori ideas about the possible distribution of their covariance error matrix; e.g. the introduction of the Minnesota prior, first highlighted by Litterman (1986). The BVAR models are very effective when incorporating many various time series with a 'jagged edge,' frequent adjustments, and revisions. They include information matrices of large dimensions, e.g. for the formulation of monetary policy, which is a common practice of many central banks (Banbura et al., 2010, 2014; De Mol et al., 2008; Giannone et al., 2012).

In our case, the selected time series were primarily aggregated into a composite indicator. Then, the statistical relationship between the dynamics of this indicator and quantitative reference series (GDP growth) were confirmed through VAR-modelling, when the behaviour of any variable depended both on its past values and on the values of other series included in the model (Mayr \& Ulbricht, 2007; Lütkepohl, 2011). Based on the literature review and in accordance with the study objective we formulate the main research hypothesis:

HO: The compatibility of cyclical dynamics of aggregate economic sentiment and GDP growth allows TESI to be used for the early estimation of economic growth, especially taking into account its timelier publication.

Several sub-hypotheses have been formulated, which are illustrated in the study using specific visual examples for different time intervals: 
H1: In periods of economic overheating, the TESI grows faster than GDP and can act as a leading indicator that anticipates cyclical reversals towards a phase of growth slowdown.

H2: The rate of growth of negative sentiments of economic agents synchronously exceeds the intensity of the slowdown in GDP growth. In such periods, the TESI is defined as a coincident indicator, which confirms the transition of economic growth to a phase of contraction.

H2: After each crisis period, there is a significant gap and lag between an intense GDP growth and a less pronounced TESI improvement. The four-year period since the 2015-2016 recession should be defined as the 'new normal' in the dynamics of entrepreneurial opinions and expectations in Russia.

H4: Each clear short-term surge in the dynamics of aggregate economic sentiment initially contributes to the synchronous expansion of economic growth, not less than by 0.6 standard deviations. The expansion continues for six months, but with a noticeably lower intensity.

A joint investigation of the TESI and the GDP growth in the context of the above hypotheses seeks to substantiate the relevance of BCS information and its use in analysing short- and medium-term prospects for the development of the Russian economy.

\section{RESEARCH METHODOLOGY}

\section{Data source}

This study is based on the results of surveys conducted by Rosstat in 85 regions of Russia and six basic sectors of the economy. ${ }^{4}$ They are conducted regularly (monthly and quarterly) and their results are published timely and not revised. To construct the TESI, we integrate the opinions and expectations of 29000 economic agents: 3100 manufacturing firms, 500 mining firms, 6000 construction organisations, 4000 retail firms, 4000 wholesale firms, 6000 services organisations, and 5100 households. $^{5}$

The surveys contain qualitative assessments and expectations: all respondents are asked about the current level, along with recent and expected changes in their business. The answers are aggregated in the form of balances, which are constructed as the difference between the percentages of positive and negative replies, i.e. an 'increase' and 'decrease' in the indicator compared to the previous period or the indicator level 'above normal' and 'below normal' in the surveyed period. The series of balances are used to build various composite indicators, harmonised as much as possible with the recommendations of the DG ECFIN and $\operatorname{OECD~}(E C, 2020)$ for cross-country comparative analysis. The quantified results of the surveys mainly reflect early measurements of current and expected business tendencies in various sectors of the economy.

\section{Research methodology}

For the TESI calculation, we use 18 quarterly indicators, from regular BCS by Rosstat, which promptly reflect the short-term fluctuations in entrepreneurial estimates of business tendencies in the Russian economy in 1998-2020. These indicators (Table 1) show the highest synchronous correlation with GDP growth.

Methodologically, the TESI consists of a harmonised set of components recommended by the EC, which we expanded by including six indicators of mining and wholesale trade. This expansion allows us to summarise the survey results in economic activities, with a total contribution to GDP of up to $70 \%$. The TESI calculation algorithm includes seasonal adjustment and the standardisation of components, their weighting according to their shares in GDP, and summing up of the components and normalising the result with an average value of 100 and a standard deviation of 10.

\footnotetext{
${ }^{4}$ The surveys were gradually introduced into state statistical practice from 1998, first by the Centre for Economic Analysis under the TACIS program (Kitrar \& Nilsson, 2003), and then, from 2009, by the Centre for Business Tendency Studies in collaboration with Rosstat (Lipkind et al., 2019). All series of survey indicators are disseminated to external users, including the OECD database. ${ }^{5}$ Survey results (time series, not seasonal adjusted) and metadata are presented on the Rosstat website (only in Russian), https://rosstat.gov.ru/leading_indicators. Survey questionnaires are presented in the album of statistical observation forms (also in Russian), https://rosstat.gov.ru/monitoring.
} 
Table 1. List of TESI components: the BCS results

\begin{tabular}{|c|c|c|c|}
\hline No. & Indicator & Attribute & $\begin{array}{l}\text { Synchronous correlation with the } \\
\text { dynamics of GDP growth }\end{array}$ \\
\hline \multicolumn{4}{|c|}{ Mining } \\
\hline 1 & Output & expectations & 0.78 \\
\hline 2 & Demand & level & 0.84 \\
\hline 3 & Stocks of finished goods & changes & 0.69 \\
\hline \multicolumn{4}{|c|}{ Manufacturing } \\
\hline 4 & Output & expectations & 0.83 \\
\hline 5 & Demand & level & 0.82 \\
\hline 6 & Stocks of finished goods & changes & 0.68 \\
\hline \multicolumn{4}{|c|}{ Construction } \\
\hline 7 & Orders book & changes & 0.69 \\
\hline 8 & Employment & expectations & 0.73 \\
\hline \multicolumn{4}{|c|}{ Retail trade } \\
\hline 9 & Economic situation & changes & 0.79 \\
\hline 10 & $\begin{array}{l}\text { Economic situation of organ- } \\
\text { isations }\end{array}$ & expectations & 0.74 \\
\hline 11 & Stocks & level (inverted sign) & 0.72 \\
\hline \multicolumn{4}{|c|}{ Wholesale trade } \\
\hline 12 & Economic situation & changes & 0.86 \\
\hline 13 & Economic situation & expectations & 0.72 \\
\hline 14 & Stocks & level (inverted sign) & 0.71 \\
\hline \multicolumn{4}{|c|}{ Services } \\
\hline 15 & Economic situation & changes & 0.80 \\
\hline 16 & Demand & changes & 0.79 \\
\hline 17 & Demand & expectations & 0.77 \\
\hline \multicolumn{4}{|c|}{ Households } \\
\hline 18 & Confidence indicator & - & 0.86 \\
\hline
\end{tabular}

Source: own study.

First, the seasonally adjusted components were standardised; in this study, we used a sample for the period 1998-2019, or 88 quarters, to standardise:

where:

$$
\mathrm{Y}_{1, \mathrm{t}}=\frac{\mathrm{X}_{1, \mathrm{t}}-\overline{\mathrm{X}_{1}}}{\mathrm{~S}_{1}}
$$

$$
\mathrm{S}_{1}=\sqrt{\frac{1}{87} \sum_{\mathrm{t}-1}^{88}\left(\mathrm{X}_{1, \mathrm{t}}-\overline{\mathrm{X}}_{1}\right)^{2}}, \overline{\mathrm{X}}_{1}=\frac{1}{87} \sum_{\mathrm{t}-1}^{88} \mathrm{X}_{1, \mathrm{t}}
$$

$\mathrm{Y}_{1, \mathrm{t}}$ - standardised value of each component;

$\mathrm{X}_{1, \mathrm{t}}$ - initial value of each component.

In the second iteration, all standardised series were weighted according to the share of each sector in $\mathrm{GDP}^{6}$ and summed. The weighted sum was divided by the sum of the assigned weights; as a result, the time series $Z(t)$ was determined:

where:

$$
Z_{t}=\frac{\sum_{j} w_{j} \cdot Y_{j, t}}{\left(\sum_{j} w_{j}\right)_{t}}
$$

$$
\mathrm{j}=\overline{1,18}
$$

$\mathrm{w}_{\mathrm{j}}$ - weight assigned to each component.

\footnotetext{
${ }^{6}$ The household sector is assigned an estimated weight of 0.10 .
} 
In the third iteration, the weighted averages were scaled to obtain a long-term average of 100 and a standard deviation of 10 :

$$
\begin{gathered}
\bar{Z}=\frac{1}{87} \sum_{t=1}^{88} Z_{1} \\
S_{Z}=\sqrt{\frac{1}{87} \sum_{t-1}^{88}\left(Z_{t}-\bar{Z}\right)^{2}} \\
\operatorname{TESI}_{t}=\left(\frac{Z_{t}-Z}{S_{Z}}\right) \cdot 10+100
\end{gathered}
$$

where:

$\overline{\mathrm{Z}}$ - period average;

$\mathrm{S}_{\mathrm{Z}}$ - standard deviation.

According to the logic of the TESI construction, the value of 100 or close to 100 identifies the business environment with an uncertain economic situation. An increase in TESI values above 100 indicates an increase of entrepreneurial optimism; a decrease to a level noticeably below 100 indicates an increase in depressive sentiment and recessionary events (crisis). TESI values significantly above $100 \mathrm{in}-$ dicate excessive optimism in the sentiments of economic agents, which is usually typical for overheating of the economy, when the market saturation of manufactured products exceeds the growth in demand. In terms of growth cycles, this situation generates an expansion, a boom. However, if the ESI falls significantly below 100 , when the output increasingly fails to meet stable or still growing demand, a gradual increase in recessionary phenomena and - accordingly - excessive pessimism and crisis sentiments of economic agents become obvious.

In our previous study, the TESI series were iteratively tested for sensitivity to a short-term cyclical profile in the dynamics of GDP growth (Kitrar et al., 2015). The algorithm for such a joint decomposition of quantitative and qualitative indicators was based on the two-sided linear Hodrick-Prescott (HP) statistical filter (Hodrick \& Prescott, 1997), according to the recommendations and relevant experience of the OECD and the EC (OECD, 2012; EC, 2020; Nilsson \& Gyomai, 2011). The HP filter computes a smoothed time series by minimising the variance of $s_{t}$ elements around $y_{t}$ :

where:

$$
\sum_{t=1}^{T}\left(y_{t}-s_{t}\right)^{2}+\lambda \sum_{t=2}^{T-1}\left(\left(s_{t+1}-s_{t}\right)-\left(s_{t}-s_{t-1}\right)\right)^{2} \rightarrow \min
$$

$\mathrm{S}_{\mathrm{t}}$ - smoothed time series.

The smoothing parameter was calculated as:

where:

$$
\lambda=\left(2 \cdot \sin \left(\frac{\pi}{\text { cut }- \text { off frequency }}\right)\right)^{-4}
$$

$$
\text { cut - off frequency - the period of smoothing. }
$$

This algorithm allowed us to extract unobservable cyclic components with a smoothed amplitude. A double pass of the HP filter should be applied for the decomposition of the TESI dynamics, if the pessimism/optimism accumulates at certain time intervals, and a low-frequency component appears in the analysed dynamics. In this case, the first HP pass at low frequencies (with $\lambda=8330.69$ ) neutralises the influence of the long-term stable component (15 years), and the second pass (with $\lambda$ $=6.885$ ) extracts a growth cycle, smoothing out fluctuations with an amplitude of less than 30 months. In the absence of low-frequency components in the primary dynamics of the indicators, only one filter pass is used at high frequencies. The logic of this calculation and the periods of smoothing were previously established empirically (Kitrar et al., 2015). 
The time series of the TESI and the GDP growth for the period from Q1-1998 to Q2-2020 were tested for stationarity using the Augmented Dickey-Fuller (ADF) test. The null hypothesis was the presence of a unit root; if it was rejected, the series were considered stationary. The obtained $p$ values of less than 0.01 for both variables for the entire observation period allowed for the rejection of the null hypothesis, and the analysed dynamics were considered stationary at the $1 \%$ significance level. Consequently, to identify the short-term cyclical profile in the TESI and GDP growth series, one pass of the HP filter was used.

Then the sensitivity of the quantified survey results to phase changes in the cyclical development of the economy was tested. The cyclical profile in the TESI dynamics was compared with the retrospective of turning points in the similar dynamics of GDP growth. The proximity of the peaks and troughs of the observed growth cycles in the indicators' co-movement and the significant synchronous correlation of the series was the main criterion for assessing the cyclical sensitivity of TESI.

As the TESI and GDP growth series are stationary, we were able to apply VAR modeling. The proposed model specification includes two jointly dependent variables: $X_{t}$ (TESI) and $Y_{t}$ (GDP growth) in which $t$ is quarters for the period from Q1-1998 to Q3-2020. The selected extreme points of the time series sufficiently affected the simulation results; the used sample length was currently available.

We proved that two lags (quarters) were the optimal lag number for this specification, based on the minimum values of generally accepted information criteria, which were determined for the model with two lags (Table 2).

Table 2. Selecting the number of lags for the model

\begin{tabular}{|c|c|c|c|c|}
\hline Lags & $\begin{array}{c}\text { Likelihood } \\
\text { logarithm }\end{array}$ & $\begin{array}{c}\text { Akaike information } \\
\text { criteria (AIC) }\end{array}$ & $\begin{array}{c}\text { Schwartz information } \\
\text { criteria (BIC) }\end{array}$ & $\begin{array}{c}\text { Hennan-Quinn infor- } \\
\text { mation criteria (HQC) }\end{array}$ \\
\hline 1 & -374.11335 & 9.746496 & 9.927781 & 9.819068 \\
\hline 2 & -358.05864 & $9.437401^{*}$ & $9.739543^{*}$ & $9.558354^{*}$ \\
\hline 3 & -355.20766 & 9.466863 & 9.889862 & 9.636197 \\
\hline 4 & -353.29068 & 9.520274 & 10.06413 & 9.737989 \\
\hline 5 & -348.52688 & 9.500689 & 10.165402 & 9.766786 \\
\hline 6 & -346.78149 & 9.5585 & 10.344069 & 9.872978 \\
\hline 7 & -345.84565 & 9.637068 & 10.543494 & 9.999927 \\
\hline
\end{tabular}

* marks the lowest values of each criterion

Source: own calculation conducted in Eviews.

Accordingly, we used a second-order VAR model of two equations, each of which (separately for $X_{t}$ and $Y_{t}$ ) included autoregressive components of the second order: $X_{t-1}, X_{t-2}, Y_{t-1}, Y_{t-2}$ :

$$
\begin{gathered}
X_{t}=c_{1}+a_{1,1} X_{t-1}+a_{1,2} X_{t-2}+a_{1,3} Y_{t-1}+a_{1,4} Y_{t-2}+a_{1,5} D_{1}+a_{1,6} D_{2}+a_{1,7} L_{1}+ \\
+a_{1,8} L_{2}+a_{1,9} L_{3}+\varepsilon_{1, t} \\
Y_{t}=c_{2}+a_{2,1} X_{t-1}+a_{2,2} X_{t-2}+a_{2,3} Y_{t-1}+a_{2,4} Y_{t-2}+a_{2,5} D_{1}+a_{2,6} D_{2}+a_{2,7} L_{1}+ \\
+a_{2,8} L_{2}+a_{2,9} L_{3}+\varepsilon_{2, t}
\end{gathered}
$$

where:

$X_{t}$ - TESI seasonal adjusted series;

$Y_{t}$ - GDP growth, y-o-y, \%;

$D_{1}$ - dummy variable for the external crisis, active (=1) for Q3-1998, Q4-2008, Q1-2009, Q2-2020, Q4-2020;

$D_{2}$ - dummy variable for recovering from a severe crisis, active (=1) for Q1-1999, Q1-2009, Q3-2020, Q1-2021;

$L_{1}$ - dummy variable for a very weak TESI fall compared to the strong GDP fall in Q3-1998;

$L_{2}$ - dummy variable for strong GDP growth without TESI growth in Q3-1999;

$L_{3}$ - dummy variable for a strong TESI fall without a GDP fall in Q1-2002, Q1-2015.

The random residuals in the equations were denoted as $\varepsilon_{1 t}$ and $\varepsilon_{2 t}$ and were white noise processes with the following distribution parameters: 


$$
\begin{aligned}
& E\left(\varepsilon_{1 t}\right)=0, \operatorname{Var}\left(\varepsilon_{1 t}\right)=\sigma^{2} \\
& E\left(\varepsilon_{2 t}\right)=0, \operatorname{Var}\left(\varepsilon_{2 t}\right)=\sigma^{2}
\end{aligned}
$$

The variables in the VAR model were stationary, endogenous, and defined within the system. The presence of delayed relationships for two quarters allowed us to classify this model as dynamic. The universality and simplicity of the proposed model were among the main advantages that guided us. The model specification was clearly limited according to the goal of the study.

We introduced dummy variables into the model specification to account for unexpected crises in the trajectory of the analysed indicators - including the last shock caused by Covid-19 lockdowns - and the fact that the 'bottom' of this episode has already been reached and a recovery has started. The lowest TESI values in Q3-1998, Q4-2008, Q1-2009, and Q2-2020 were initially provoked by the 'unexpected shocks' of mostly non-economic nature. In this case, any variable 'crisis' had a value of 1 , and for the rest of the dynamics, 0 . To fix the recovery period the variable 'recovery' was activated (with a value of 1). This allowed us to take into account the specifics of this period in the short- and mediumterm forecasting of GDP growth without over-complicating the model.

The proposed model specification with dummy variables (formulas 8,9 ) was evaluated as consistent. According to the Doornik-Hansen test, for the first four lags, the null hypothesis of the normal distribution of residuals was not rejected at the $5 \%$ significance level ( $p$-value 0.177 ). The hypothesis of no autocorrelation according to the Broysch-Godfrey test was not rejected at the $5 \%$ significance level ( $p$-values for each lag are higher than 0.05). ${ }^{7}$

The VAR-simulation results are presented in Table 3.

\begin{tabular}{|c|c|c|c|c|c|c|c|c|}
\hline \multirow[t]{2}{*}{ Lags } & Coefficients & $\begin{array}{c}\text { Standard } \\
\text { error }\end{array}$ & t-statistics & $p$-values & Coefficients & $\begin{array}{c}\text { Standard } \\
\text { error }\end{array}$ & t-statistics & p-values \\
\hline & \multicolumn{4}{|c|}{ Equation: GDP } & \multicolumn{4}{|c|}{ Equation: TESI } \\
\hline const & 16.97 & 3.85 & 4.41 & 0.00 & 7.90 & 7.92 & 0.99 & 0.32 \\
\hline$X_{1}$ & 0.08 & 0.04 & 2.13 & 0.04 & 0.86 & 0.08 & 10.62 & 0.00 \\
\hline$X_{2}$ & -0.09 & 0.04 & -2.45 & 0.02 & -0.17 & 0.08 & -2.15 & 0.03 \\
\hline$Y_{1}$ & 1.07 & 0.08 & 13.36 & 0.00 & 0.38 & 0.16 & 2.28 & 0.03 \\
\hline$Y_{2}$ & -0.23 & 0.08 & -2.91 & 0.01 & -0.15 & 0.16 & -0.93 & 0.36 \\
\hline $\mathrm{D}_{1}$ & -8.79 & 0.68 & -12.86 & 0.00 & -22.78 & 1.41 & -16.19 & 0.00 \\
\hline$D_{2}$ & 5.20 & 0.96 & 5.41 & 0.00 & 16.70 & 1.98 & 8.45 & 0.00 \\
\hline $\mathrm{L}_{1}$ & 0.59 & 1.51 & 0.39 & 0.69 & 13.09 & 3.11 & 4.20 & 0.00 \\
\hline $\mathrm{L}_{2}$ & 6.49 & 1.33 & 4.87 & 0.00 & -1.12 & 2.74 & -0.41 & 0.68 \\
\hline $\mathrm{L}_{3}$ & -2.86 & 1.30 & -2.20 & 0.03 & -10.89 & 2.67 & -4.08 & 0.00 \\
\hline
\end{tabular}

Table 3. Results of the VAR simulation

Source: own calculation conducted in Eviews.

The results of the Granger causality test (Table 4) showed that there are dependencies of the TESI in the GDP growth and the GDP growth in the TESI.

Table 4. Granger causality test results

\begin{tabular}{|c|c|c|c|}
\hline Hypothesis & Chi-square & p-value & Result \\
\hline TESI does not affect GDP growth & 3.2364 & 0.0446 & Rejected \\
\hline GDP growth does not affect TESI & 3.1243 & 0.0494 & Rejected \\
\hline
\end{tabular}

Source: own calculation conducted in Eviews.

We used the impulse response function (IRF) to clarify the relationship between two series in the model and to estimate the strength and direction of the shock, and the duration of adjusting the estimated series (GDP growth) to the shock in TESI equal to one standard deviation. To identify

\footnotetext{
${ }^{7}$ All test results are available upon request.
} 
shocks, the Cholesky decomposition was used; the order of the variables was set by variance decomposition. The optimal ordering provided the greater impact of the TESI on the dependent variable (the GDP growth). This result of variance decomposition of GDP series was achieved with the following ordering of the variables: the TESI $\rightarrow$ the GDP growth. In this ordering, shocks in economic sentiment affected both the TESI and the GDP growth, while shocks in the GDP growth had an immediate impact only on economic growth. Therefore, we were considering a situation when GDP growth does not have a leading effect on economic sentiment.

The IRF reflects the statistically significant relationship between the variables in the model used to calculate scenario forecasts of GDP growth. The calculations were conducted by taking into account possible gaps in the TESI at the end of 2020 relative to the long-term average level of its dynamics.

On the in-sample interval (from the Q1-1998 to Q1-2020), the model acceptability for the quarterly forecast was confirmed based on parameters of the forecast quality (Table 5).

Table 5. Parameters of the forecast quality

\begin{tabular}{|l|r|l|r|l|r|}
\hline \multicolumn{2}{|c|}{ Forecast without dummies } & \multicolumn{2}{c|}{ Forecast with dummies } & \multicolumn{2}{c|}{ Forecast without pandemic shock } \\
\hline R-squared & 0.78 & R-squared & 0.93 & R-squared & 0.93 \\
\hline Sum sq. resids & 542.54 & Sum sq. resids & 130.29 & Sum sq. resids & 116.88 \\
\hline S.E. equation & 2.32 & S.E. equation & 1.29 & S.E. equation & 1.24 \\
\hline MSE & 5.08 & MSE & 1.46 & MSE & 1.34 \\
\hline RMSE & 2.26 & RMSE & 1.21 & RMSE & 1.16 \\
\hline ME & 4.38 & ME & 4.15 & ME & -4.48 \\
\hline MAE & 1.41 & MAE & 0.94 & MAE & 0.87 \\
\hline MAPE & 0.01 & MAPE & 0.01 & MAPE & 0.01 \\
\hline
\end{tabular}

Source: own calculation conducted in Eviews.

The proposed method of analysis largely illustrates the potential of an empirical approach, which is available to most researchers and experts and is flexible and convenient for solving more complex problems that require the introduction of additional indicators and the complication of the model specification of their relationship.

\section{RESULTS AND DISCUSSION}

\section{Visualisation, cross-correlation, and scatter diagram}

Figure 1 presents the time series of the TESI and the GDP growth (1998-2020). According to our estimates, the minimum value of the TESI in Q1-2015 signalled the beginning of a decrease in aggregate uncertainty, anticipating preliminary estimates of economic growth at that time. Since mid-2018, after short-term episodes of growth in entrepreneurial optimism, the uncertainty of opinions and expectations has periodically increased, bordering on pessimism. In Q2-2020, we observed the sharpest and almost vertical collapse of the aggregate sentiment of Russian entrepreneurs and households. The sudden and unprecedented TESI drop was obviously associated with strict measures to contain the pandemic, which had an extremely adverse effect on business and the population both on the demand (reduced household consumption, investment activity, export earnings) and supply side (a decline in production and services, disruptions in production and supply chains).

The primary visual and cross-correlation analysis of the TESI and GDP growth dynamics revealed a statistically significant relationship with a high value of the synchronous correlation coefficient of 0.86 . The prompt calculation of the TESI - almost two months ahead of the first quantitative estimate of the GDP growth - and the stable synchronous correlation between these series are the first evidence of the feasibility of using the TESI as an early estimate of possible changes in economic growth. This allowed us to continue the examination of TESI dynamics for its accuracy for early estimates of the change in economic growth rates. 

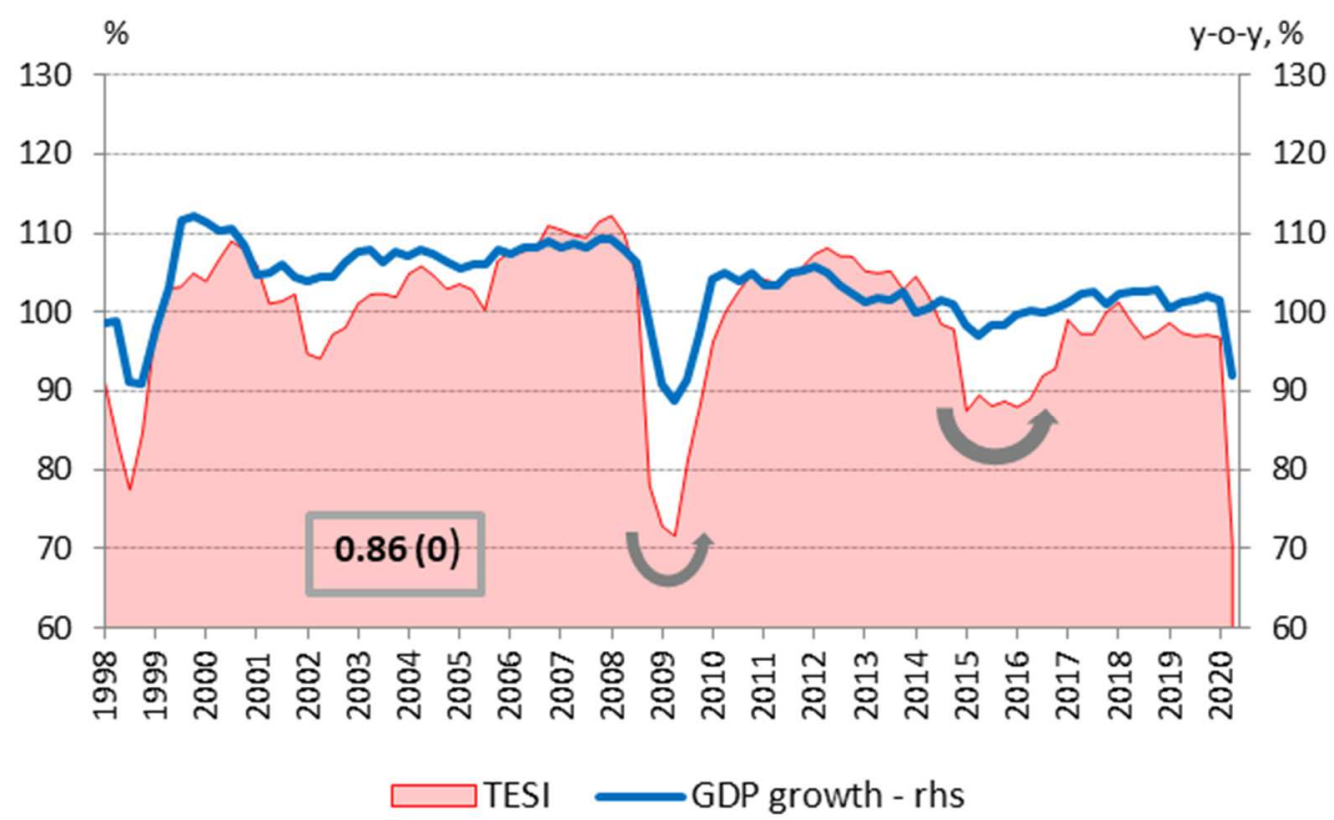

Figure 1. TESI and GDP growth dynamics in 1998-2020

Note: The marker indicates the coefficient of synchronous correlation between the TESI and GDP growth series. Source: own elaborations based on Rosstat data.

The scatter diagrams shown in Figure 2 enhance the visualisation of the general correspondence between TESI and GDP growth and allow us to illustrate the sub-hypotheses of the study. The different sets of points (I-V) are also presented separately.

According to this visualisation, relationships can be traced in the dynamics of the TESI and the GDP growth at different time intervals. With an increase (decrease) in TESI values, the GDP growth changes in a similar direction. However, in different periods of cyclical development, the relationships between the levels of time series differ.

A significant improvement in the TESI throughout the analysed period was consistently associated with the phase of accelerating economic growth ( $\mathrm{H} 1)$. In the range of the highest values of the indicators - corresponding to the periods of the most successful economic development (the economy overheating) - the TESI largely grew faster than GDP (Figure 2a). High entrepreneurial optimism signalled a new expansion of gross value added. In the phase of accelerating economic growth, the TESI was one of leading short-term indicators that anticipated cyclical reversals to growth, especially from the moment when a steady excess of TESI values over GDP growth rates was recorded.

The set of extremely low values of both indicators clearly shows the inverse relationship (Figure 2e). During periods of economic downturn, the most intense growth in the TESI is observed (H2). In the recession phase, the TESI can also be defined as an indicator that warns in advance about the crisis' aggravation, from the moment when its values are less than 100 and become noticeably lower than similar values of GDP growth.

In different periods of economic stabilisation, the TESI was lower than the GDP growth rates and remained almost synchronous. Any upward deviations in entrepreneurial confidence signalled a stable economic situation (Figure $2 b$ ).

Fluctuations in the TESI during periods of economic uncertainty had largely uneven and low amplitudes (Figure 2c). After each clear crisis period, there was a significant gap and lag between intensive GDP growth and a less pronounced improvement in economic sentiment (Figure 1; H3). At the epicentre of the recession of 2014-2016, the aggregate confidence (the TESI) declined at a noticeably larger scale relative to the change in the GDP growth (Figure $2 \mathrm{~d}$ ). 

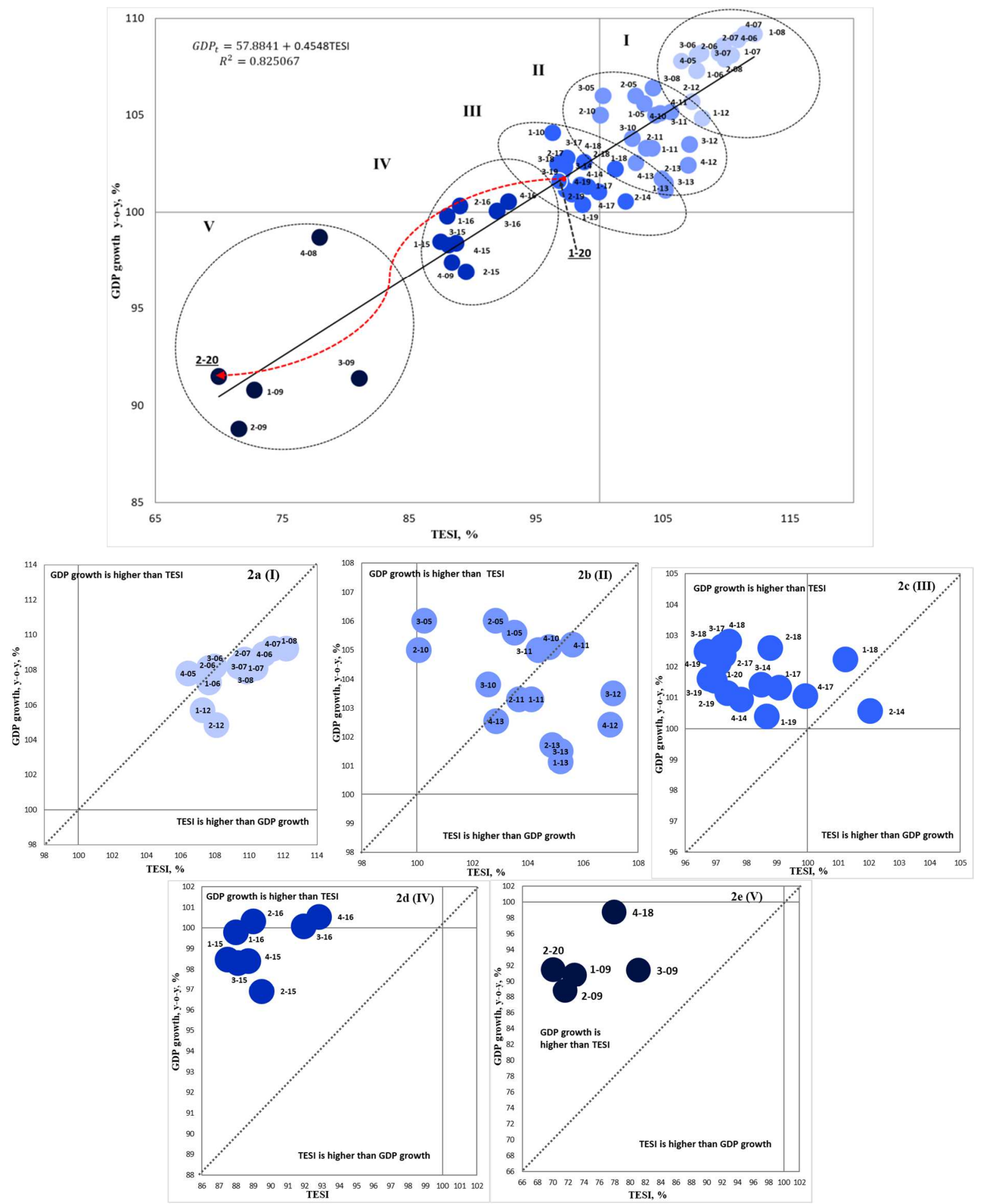

Figure 2. Scatter chart of GDP growth and TESI in the 2005-2020 period

Note: Light markers (the set of points I) indicate periods of the boom of optimism and the peak of GDP growth with quarters of economy overheating at the intersection of the highest values; set II - high TESI values and high GDP growth; set III - neutral TESI values and low GDP growth; set IV - low TESI values and a moderate decline in GDP; dark markers (V) - extremely low TESI values and the recessions of economic growth with crisis quarters at the intersection of the lowest values. Source: own elaborations based on Rosstat data.

Our conclusion based on the empirical analysis of the relationship between the TESI and the GDP growth is consistent with the main hypothesis. To ensure the highest rates of economic development, it is necessary to strengthen the parameters of business activity and a high level of entrepreneurial 
confidence. Conversely, weakening positive economic trends is accompanied by a faster increase in negative business sentiment compared to a slowdown in the GDP growth. Thus, the empirical result of the joint visual assessment of the two macro indicators shows that at the upper and lower turns of cyclical economic development, the TESI reacts more strongly and corresponds to upcoming economic events more clearly, becoming their precursor. Stabilisation periods correspond to more restrained intentions of economic agents with the prevailing uncertainty of estimates.

However, the level of aggregate entrepreneurial confidence over the period of the protracted recession of 2015-2016 decreased significantly; as a result, even with an increase in TESI values, all of its subsequent four-year dynamics were characterised by the lowest potential compared with the recovery periods after previous crises; lower than the corresponding intensity of economic growth (H3). The post-crisis economic reality can be defined as the 'new normal' for the cumulative dynamics of entrepreneurial opinions and expectations. Studies devoted to the dynamics of BCS results in the EU came to similar conclusions (Gayer \& Mark, 2016; Astolfi et al., 2016). The bottom line is that the sentiment of business and consumers - not recovered from the crisis even to the previous (normal) level - was again pulled into uncertainty and high volatility when the crisis phase was only smoothed out and upward trends manifested mainly in the case of a low base effect.

\section{Decomposition of the TESI sectoral structure and cross-countries comparisons}

Current trends in the annual TESI dynamics are determined by the potential and scale of the growth of its sectoral components. Figure 3 with four quadrants presents the TESI sectoral decomposition at a point in time according to the current level and annual growth of TESI components.

The main thesis in this regard is that industries that have a high level of entrepreneurial confidence and develop more intensively have much more potential. Other industries, even those with high activity at the moment - but growing at a slower pace or stagnating - are defined as having less potential and 'catching up' in terms of developing aggregate optimism.

The main negative impulses for the TESI annual change before the corona crisis (top panel) were generated by a decrease in entrepreneurial confidence in mining (components 1 and 2), retail, and wholesale trade (components 9-14). Economic sentiment in the construction and consumer sectors improved, but the components remained low and far from the quadrant of confidence growth. In manufacturing and services, the indicators were fixed practically on the border with the cyclical phase of growing uncertainty. In Q2-2020 (bottom panel), at the height of the pandemic in Russia and the strictest lockdowns, a sharp increase in pessimism of entrepreneurs in services (components 15 and 16) was the main driver of the negative TESI dynamics.

A comparison of the Russian TESI with similar information in the EU is also feasible due to the high harmonisation of Russian and European surveys in terms of questions, data treatment, and aggregation methods. The joint visualisation of economic sentiments indirectly reflects the shortterm expected fluctuations in GDP growth, based on the statistically significant correlation between TESI and the macro-referent (EC, 2016, 2017). The results of this analysis of economic sentiment in Europe and Russia are presented in Figure 4, which shows the position of each country in a particular quadrant of TESI changes.

At the initial stage of lockdowns in Q1-2020 (top panel), most countries were located in the quadrants of stagnation or crisis of confidence, and TESI values were evenly distributed in the range from 90 to 110 . The different rates of TESI decline in European economies were largely explained by different timing of the survey in March 2020, regarding the adoption of strict restrictive measures to contain the pandemic in these countries. In the second quarter, negative sentiments sharply increased in all European countries, all assessments moved deep into the quadrant of a crisis of confidence. 

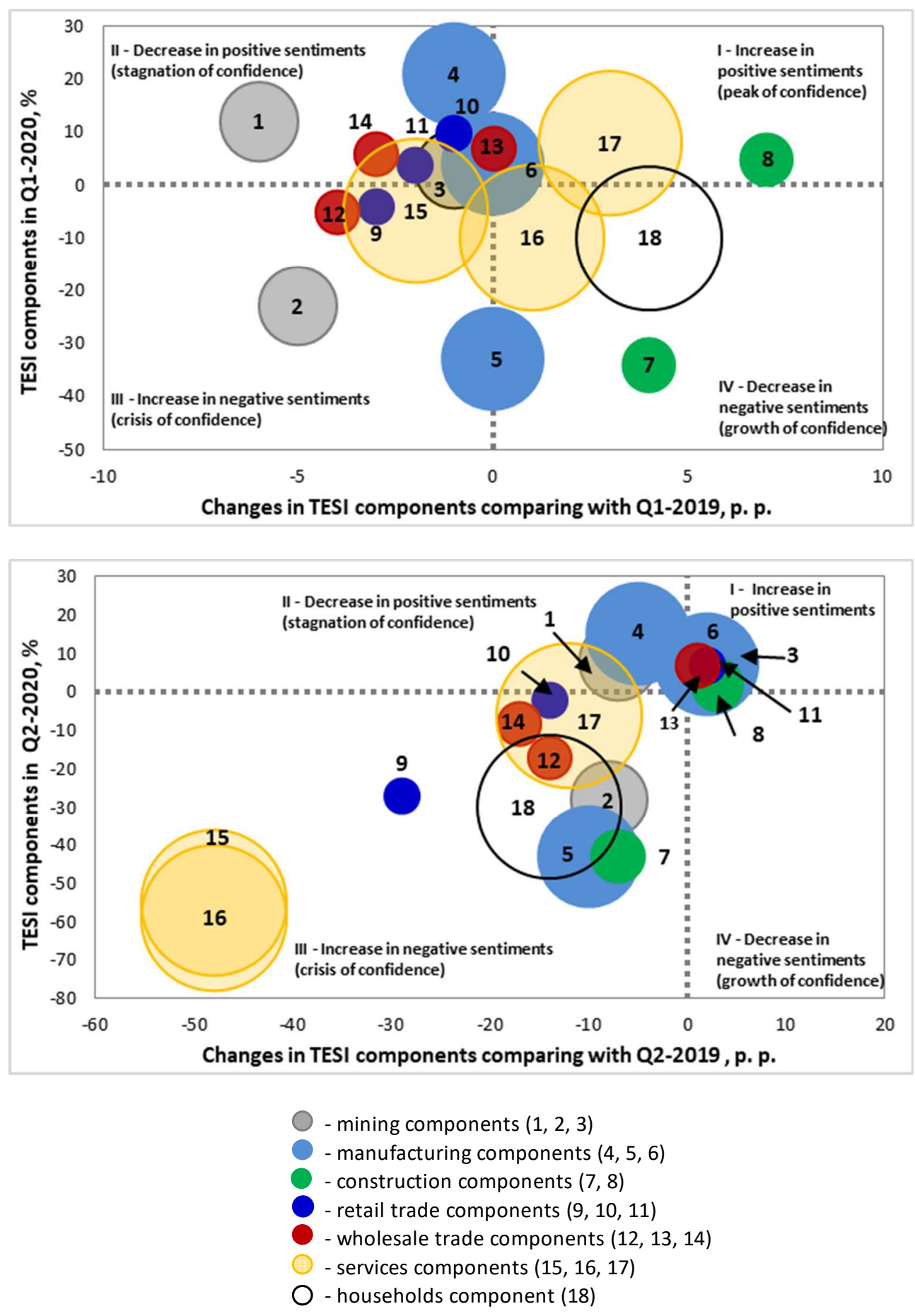

Figure 3. The TESI decomposition in 2020: levels and annual growth of sectoral components Note: The markers' sizes are determined by the shares of each sector in the TESI structure. Indicators are numbered according to Table 1. Source: own elaborations. 

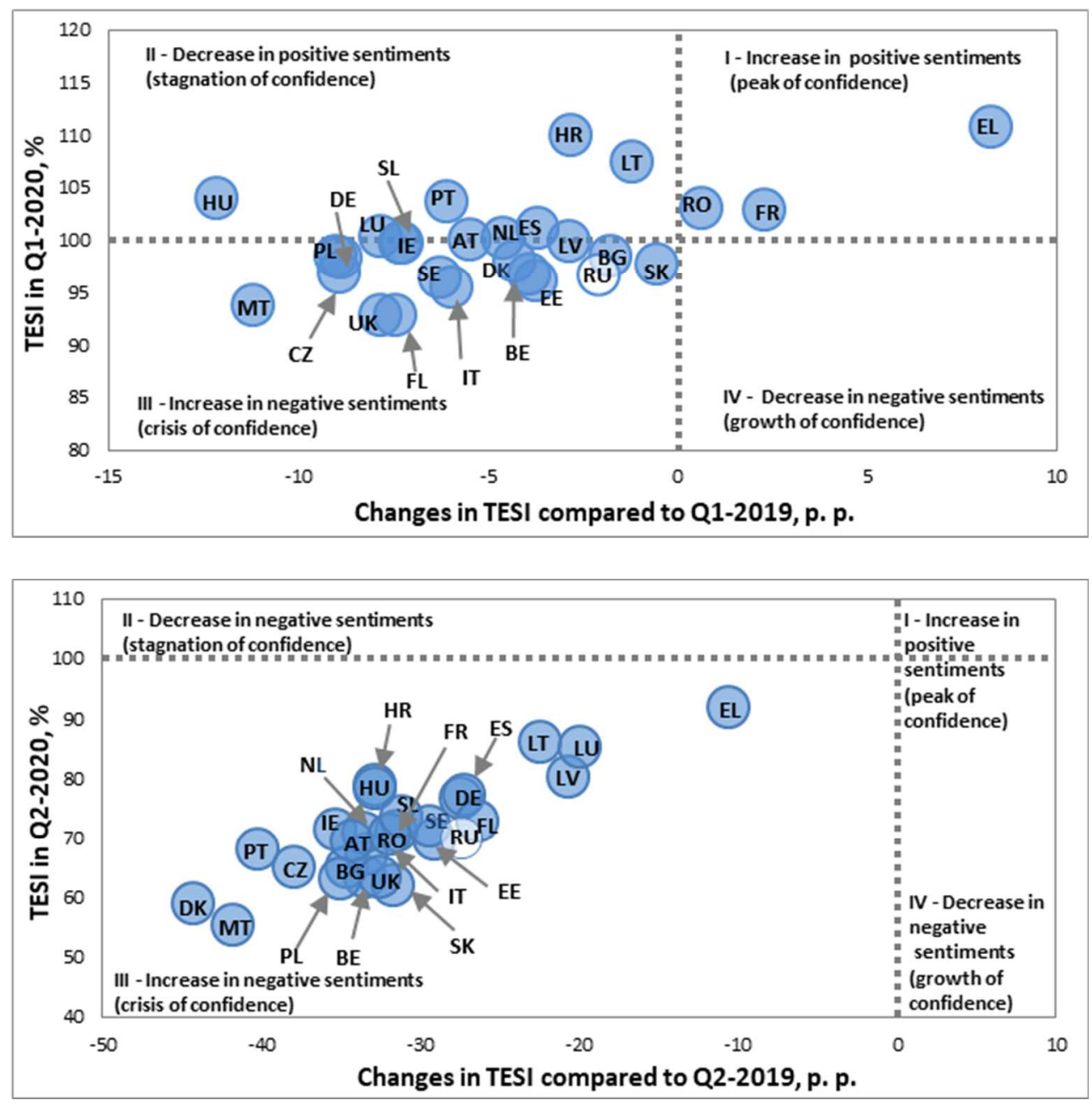

Figure 4. Economic sentiment in European countries and Russia in 2020

Note: Quarterly data for European countries is obtained by averaging monthly data (for comparability with Russian data). AT - Austria, BE - Belgium, BG - Bulgaria, CZ - Czech Republic, DK - Denmark, DE - Germany, EE - Estonia, EL - Greece, ES - Spain, FL - Finland, FR - France, IE - Ireland, IT - Italy, HR - Croatia, HU - Hungary, LV - Latvia, LT - Lithuania, LU - Luxembourg, MT - Montenegro, NL - Netherlands, PL - Poland, PT - Portugal, RO - Romania, SL - Slovenia, SK - Slovakia, SE - Sweden, UK - Great Britain

Source: own elaboration based on EC business and consumer survey database.

\section{Joint cyclical testing of the TESI and the GDP growth time series}

At the next stage, the TESI dynamics were tested for statistical sensitivity to short-term cycles in GDP growth. The results of the time series decomposition - the smoothed growth cycles in the dynamics of TESI and GDP growth in 1998-2020 - are presented in Figure 5.

The results of joint graphical visualisation and the cross-correlation analysis of the smoothed cyclic dynamics of the TESI and the GDP growth confirm a stable synchronous correlation of short-term growth cycles in these time series: $0.89 .{ }^{8}$ The turning points in the growth cycles are almost identical and are identified using the traditional Bry-Boschan procedure (Bry \& Boschan, 1971).

We empirically identified the dominant growth cycles in the dynamics of the two indicators from Q1-1998 to mid-2020. During this period, four completed (from peak to peak) growth cycles with expansion phases and contraction phases were identified. The fourth cycle in the TESI dynamics began in Q2-2012 after a period of economic overheating (with the peak in Q4-2011) and the subsequent boom of the optimism of economic agents. This cycle was the longest in the history of cyclical analysis

\footnotetext{
8 The TESI lag at the beginning of 2012 is due to a shift in the TESI level resulting from changes in the sample (services organ-
} isations were added). 
of modern economic dynamics in Russia. For almost a year, since mid-2014, the economy remained in a phase of recession, crisis events, and depressed economic sentiment. However, then we can observe the 'cognitive shift' in the level of aggregated economic sentiment. After the protracted recession of 2015-2016, its subsequent four-year dynamics was characterised by the lower potential compared to the recoveries after all previous crises. The coronavirus pandemic and quarantine measures taken in April-May 2020 led to a sharp and deep decline in economic activity. According to estimates of GDP growth in Q2-2020, this period can be defined as the immersion of the economy in a new crisis, the onset of which was caused mainly by non-economic factors. ${ }^{9}$

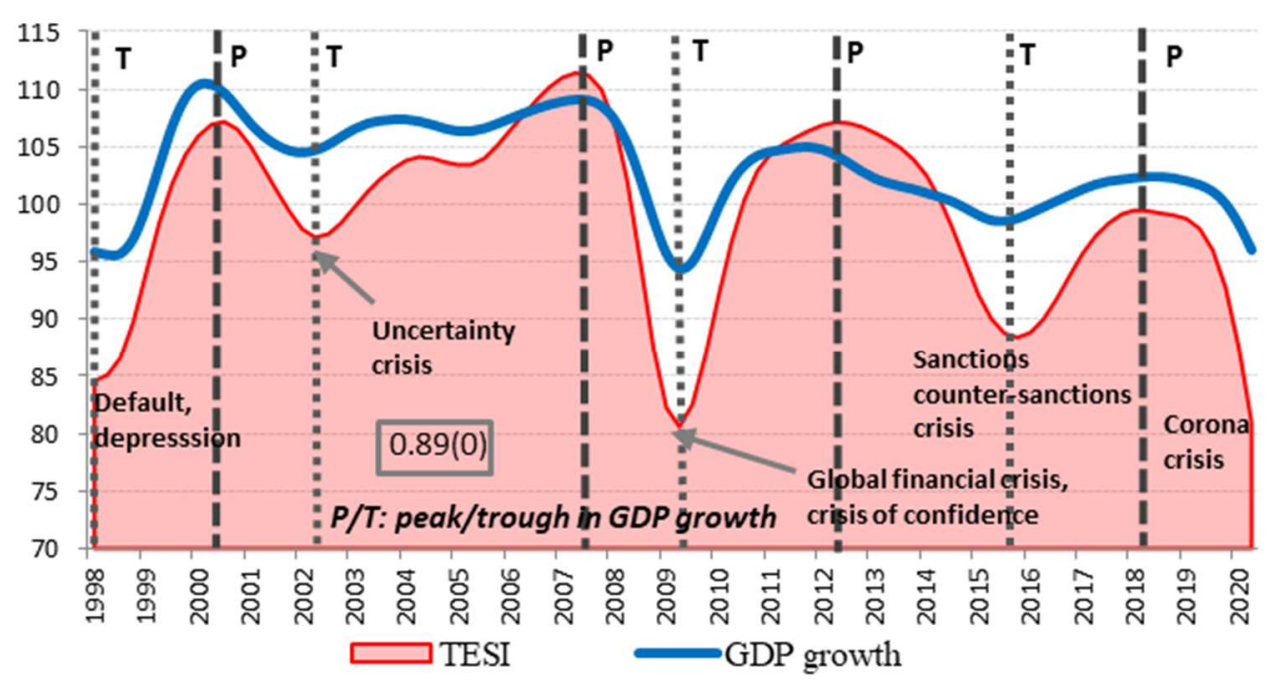

Figure 5. Short-term cycles in the TESI and GDP growth dynamics in 1998-2020

Note: The marker indicates the coefficient of synchronous correlation between the TESI and GDP growth cycles.

Source: own calculations, one pass of the HP filter.

The visualisation of the cyclical movement of economic sentiment is achieved through a tracer (Figure 6), which is based on the EC concept in terms of the diagram quadrants and the direction of the tracer movement (EC, 2019; Gayer, 2008).

The tracer clearly shows the last two complete growth cycles in the TESI dynamics since Q32007. The tracer passed the last cyclic trough in the second half of 2015 , when the aggregate economic sentiment reached its lowest value over the past seven years. The transition of the tracer to the quadrant of recession slowdown and a decrease in pessimism in Q1-2016 reflected the beginning of the cyclical recovery in TESI growth. Since mid-2018, the tracer has moved deeper into the third quadrant, indicating increased pessimism and pronounced recessionary sentiments.

Thus, the joint decomposition of the TESI and the GDP growth series with the extraction of short-term growth cycles and the dating of cyclical turning points allow us to note the cyclical conformity of the dynamics of economic indicators. We believe that the TESI - by its nature - has leading capabilities, since the timeliness of collecting the relevant data allows it to be published much earlier than GDP growth.

\footnotetext{
${ }^{9}$ The experts from the Committee on Dating Business Cycles of the US National Bureau of Economic Research (NBER) made the same conclusion; they determined the peak of quarterly economic activity in the US in the Q4-2019.The Committee acknowledged that the pandemic and the public health response had led to a recession with unusual characteristics and dynamics. Nonetheless, NBER experts believe that the unprecedented large-scale decline in employment and output - and its widespread impact on the entire economy - justify identifying this episode as a recession, even if it could be shorter than previous recessions (see https://www.nber.org/cycles/june2020.html).
} 


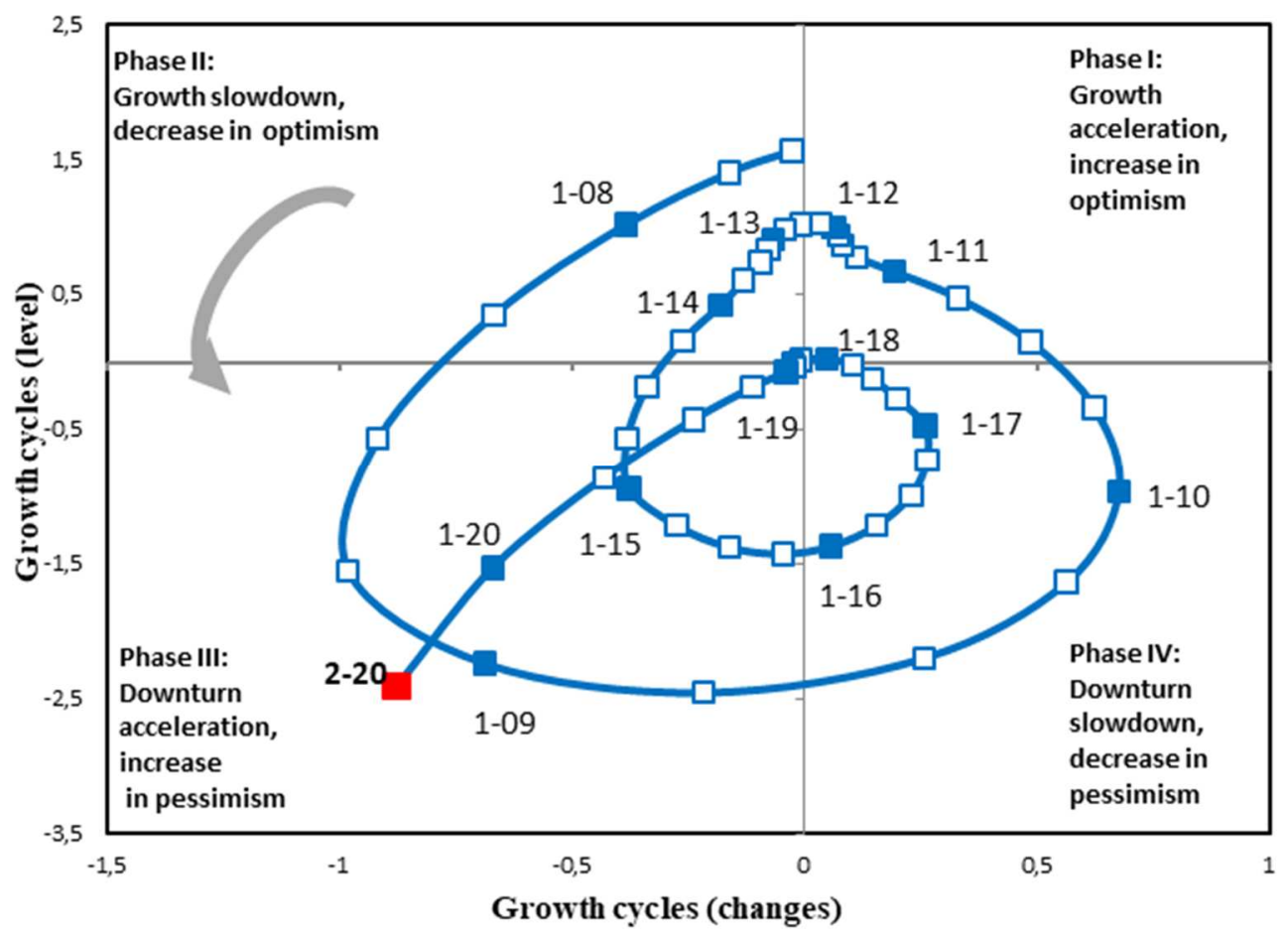

Figure 6. Tracer of cyclic profile in the TESI dynamics in 2007-2020

Note: The upper and lower values located within the central vertical line indicate the turning points of the growth cycles of economic sentiment: the peaks of overheating (optimism) and the troughs of crisis (depression). Values grouped around zero are more likely to correspond to uncertain sentiments.

Source: own elaborations based on EC concept, one pass of the HP filter.

\section{The early estimates of quarterly GDP growth based on VAR simulation results}

The results of the VAR simulation through the IRF (Figure 7) allows us to estimate the strength and direction of the impact of an artificial shock in the TESI series on the GDP growth and the duration of the GDP growth adjustment to the shock. On this basis, $\mathrm{H} 4$ is proved, i.e. a significant unidirectional relationship of two indicators is confirmed: each clear surge (equal to one standard deviation) in the TESI dynamics initially contributes to the expansion of economic growth by 0.6 standard deviations, which continues in the next quarter, but with a lower intensity (H4).The response of the GDP growth to an impulse in the TESI fades for at least six quarters, and then the reference indicator stabilises for five consecutive quarters, reaching its initial level.

We calculated scenario forecasts for GDP growth until the end of 2021 driven by the GDP response to actual and expected impulses in the dynamics of the aggregate economic sentiment from Q1-1998 to Q3-2020. Consequently, the calculations were based on the indicator values for the entire period, including a sharp decline in its dynamics due to the Covid-19 crisis.

Moreover, we introduced an expertly set interval of TESI values that are possible in Q4-2020 if expectations were to remain uncertain; in particular, due to large-scale vulnerability and slow recovery of the most affected activities, new local lockdowns, the pressure of external and internal challenges, delays in the vaccination of the population and other preventive antiviral measures. The simulation of TESI values was conducted by the input of conditional impulses as deviations from the long-term average value (100), depending on the potential of new crisis shocks at the end of 2020.

The first scenario forecast of the GDP growth (Figure 8) is associated with a more optimistic version of the TESI decline in Q4-2020 (by 0.5 standard deviations). The moderate scenario forecast was calculated based on the possible TESI falling by 1.5 and the most pessimistic scenario assumes a new strong contraction of aggregate economic sentiment by 2.5. Figure 8 also presents expected estimates of GDP growth if the coronavirus shock had not occurred in Q2-2020. 


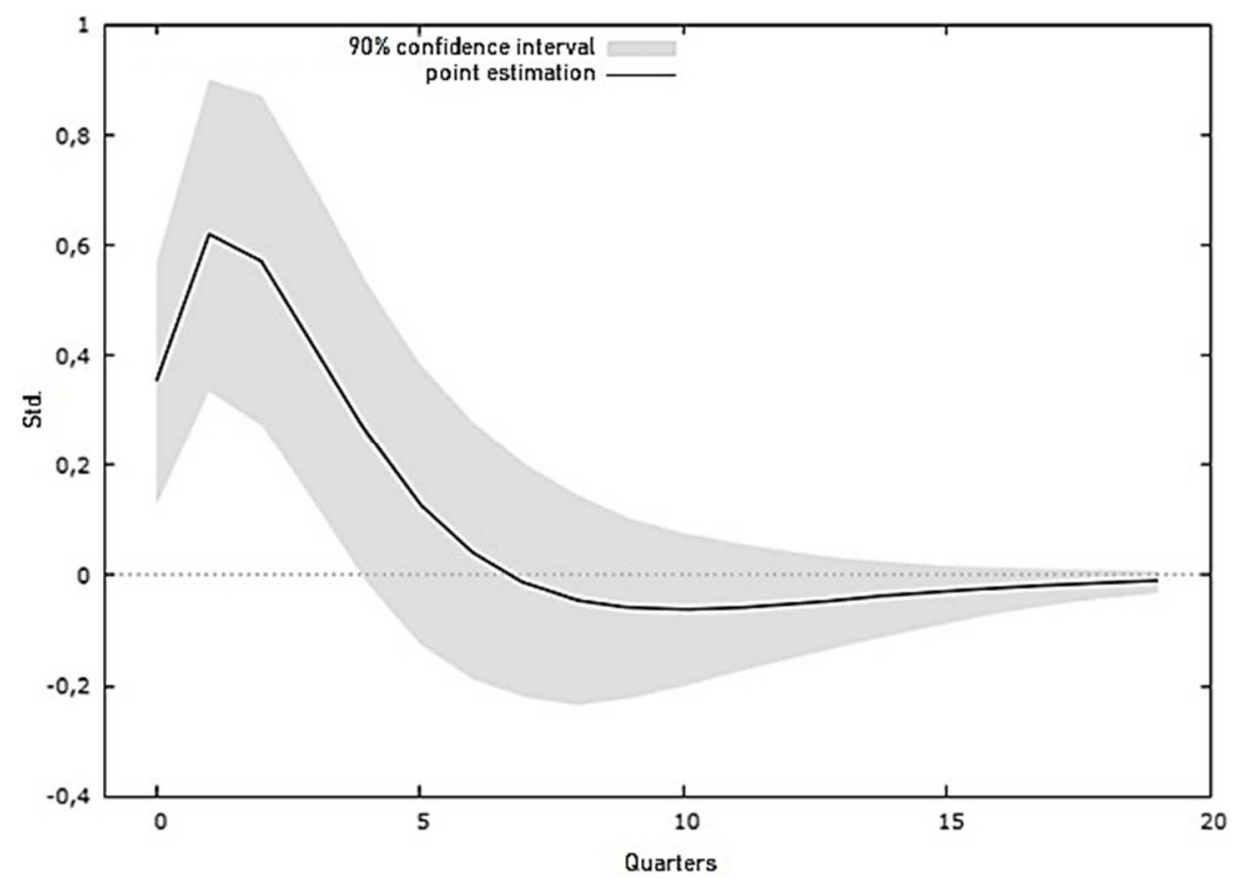

Figure 7. The response of the GDP growth to the impulse in TESI: the degree and direction of impact (Cholesky decomposition) Source: own calculation conducted in Eviews.

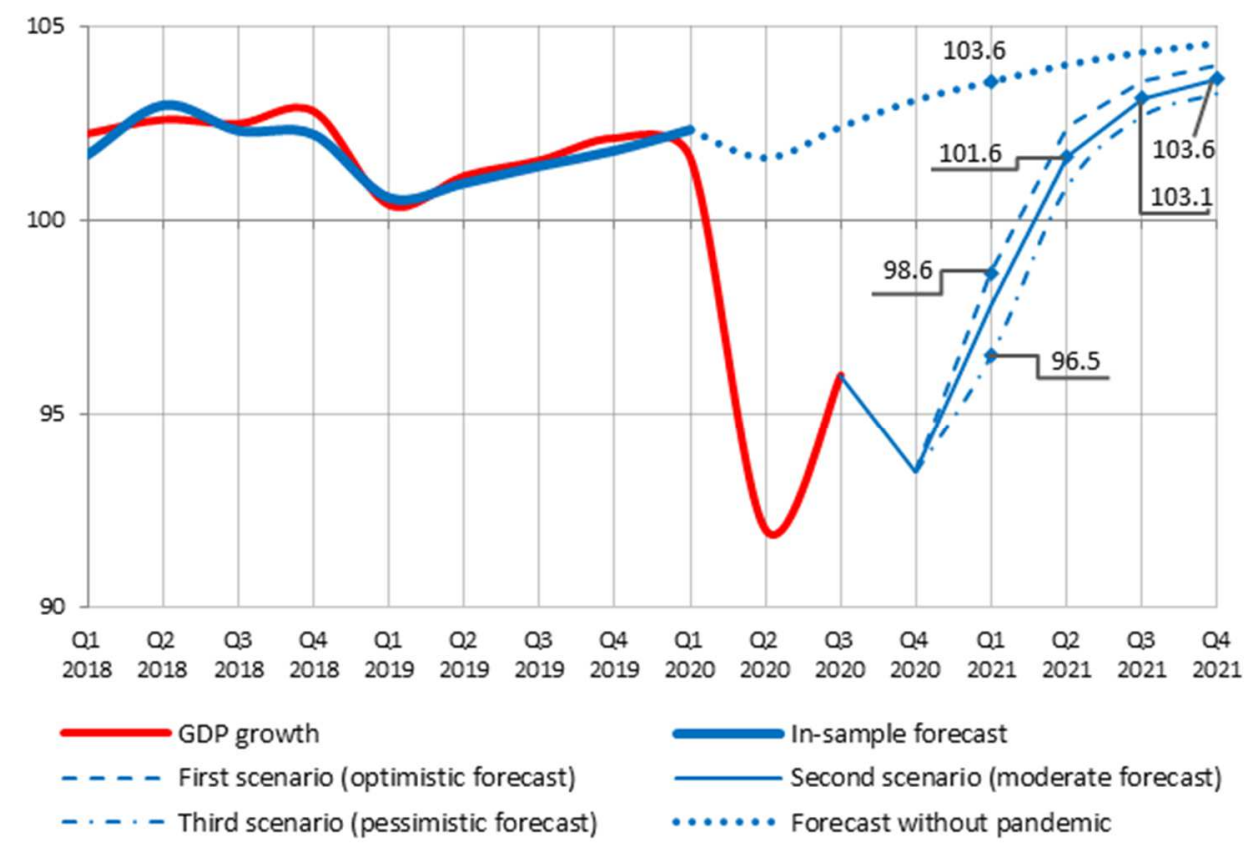

Figure 8. Scenario forecasts of GDP growth

Note: For the period from Q1-2018 to Q1-2020, the blue line denotes in-sample forecast. Source: own calculations based on Rosstat data.

The forecast results are based on the dynamic relationship of two series with the response of the estimated variable (GDP growth) to the reaction of the business environment and to the simulation of the variations we set in the TESI dynamics, which reflect possible economic sentiments under crisis 
events at the end of 2020. The results clearly indicate the replacement of the sluggish growth of Russian GDP, observed over the past two years, with an even lower trajectory. According to the calculations, the expected estimates of the economic growth in the first half of 2021 - caused by the previous values (actual and target) in the TESI dynamics - may differ between the extreme forecasts of the GDP growth by two percentage points, on average. Nevertheless, under all scenarios for the development of business trends in Q4-2020 - if we do not take into account the possible further aggravation of risks for business and consumers - the economic growth can exceed the level of the end of 2019 from Q32021. In particular, according to the moderate scenario, the GDP growth will amount to $103.6 \%$ in Q42021. National economic growth could return to a phase of sustainable recovery in 2022 only if the Covid-19 crisis is limited, local, and short-term - when only some sectors of the economy are affected - and assuming the introduction of rapid vaccinations in early 2021, full control over the viral situation, and the strengthening of business confidence.

\section{CONCLUSIONS}

The results of our study confirm the empirical and predictive value of the aggregated results of business and household surveys for assessing economic growth in Russia. The joint decomposition of the TESI and the GDP growth time series with the identification of short-term cycles proved the hypothesis of their almost synchronous cyclical conformity. However, the TESI has leading capabilities, since the timeliness of collecting the relevant data allows it to be published much earlier than the GDP growth.

Statistically significant results of the VAR-modeling with dummy variables - which fix the periods of deep economic recessions (including those associated with the coronavirus crisis) - enable the performance of short-term forecasting of the GDP growth. Given the expected impact of various new coronavirus shocks, all scenario forecasts indicate a slow recovery of economic growth, reaching the level from the end of 2019 in the second half of 2021 only.

Thus, the long-term BCS results - which summarise estimates of entrepreneurial and household sentiment over the past 23 years - are reliable as early warning information on the economic growth in Russia. We deem these results applicable for assessing the impact of crisis on business tendencies and economic growth in any resource-dependent and service-dependent economy with deep institutional interventionism, especially for emerging market countries.

The main limitation of the study is that for short-term forecasts of the GDP growth we use only a composite indicator that summarises the survey results. Despite the consistency of the proposed model specification, we assume that forecasting performance can improve if quantitative economic variables are included in the model. Another area for the further development of survey-based methods of analysis and forecasting is the improvement of the TESI leading properties by updating its composition and selecting the optimal set of components.

\section{REFERENCES}

Angelini, E., Camba-Méndez, G., Giannone, D., Rünstler, G., \& Reichlin, L. (2008). Short-term forecast of euro area GDP growth. ECB Working Paper, 949. Retrieved from https://ssrn.com/abstract=1275821 on August 1, 2020.

Astolfi, R., Gamba, M., Guidetti, E., \& Pionnier, P.A. (2016). The Use of Short-Term Indicators and Survey Data for Predicting Turning Points in Economic Activity: A Performance Analysis of the OECD System of CLIs during the Great Recession. OECD Statistics Working Papers, 2016/08. https://doi.org/10.1787/5jlz4gs2pkhf-en

Bachmann, R., Elstner, S., \& Sims, E.R. (2013). Uncertainty and economic activity: Evidence from business survey data. American Economic Journal: Macroeconomics, 5(2), 217-249. https://doi.org/10.1257/mac.5.2.217

Banbura, M., \& Runstler, G. (2007). A look into the factor model black box-publication lags and the role of hard and soft data in forecasting GDP. ECB Working Paper, 751. Retrieved from https://ssrn.com/abstract=984265 on August 1, 2020.

Banbura, M., Giannone, D., \& Reichlin, L. (2010). Large Bayesian VARs. Journal of Applied Econometrics, 25(1), 71-92. https://doi.org/10.1002/jae.1137 
Banbura, M., Giannone, D., \& Lenza, M. (2014). Conditional forecasts and scenario analysis with vector autoregressions for large cross-sections. ECARES Working Paper, 15.

Basselier, R., de Antonio Liedo, D., \& Langenus, G. (2017). Nowcasting real economic activity in the euro area: Assessing the impact of qualitative surveys. National Bank of Belgium Working Paper, 331. Retrieved from https://www.nbb.be/doc/ts/publications/wp/wp331en.pdf on August 2, 2020.

Bernanke, B., Boivin, J., \& Eliasz, P. (2005). Measuring the effects of monetary policy: A factor-augmented vector autoregressive (FAVAR) approach. The Quarterly Journal of Economics, 12, 387-422. https://doi.org/10.3386/w10220

Biau, O., \& D'Elia, A. (2011). Is There a Decoupling Between Soft and Hard Data? The Relationship Between GDP Growth and the ESI. In Proc. of the Fifth Joint EU-OECD Workshop on International Developments in Business and Consumer Tendency Surveys, Brussels. 2011, 17-18 November.

Bloom, N. (2014). Fluctuations in Uncertainty. Journal of Economic Perspectives, 28(2), 153-176. https://doi.org/10.1257/jep.28.2.153

Bonadio, B., Huo, Zh., Levchenko, A., \& Pandalai-Nayar, N. (2020). Global Supply Chains in the Pandemic. CEPR Discussion Paper, DP14766. Retrieved from https://ssrn.com/abstract=3603998 on August 1, 2020.

Bry, G., \& Boschan, Ch. (1971). Cyclical Analysis of Time Series: Selected Procedures and Computer Programs. New York: National Bureau of Economic Research.

Cesaroni, T. (2011). The Cyclical Behavior of the Italian Business Survey Data. Empirical Economics, 41(3), 747768. https://doi.org/10.1007/s00181-010-0390-7

Cesaroni, T., \& lezzi, S. (2017). The Predictive Content of Business Survey Indicators: Evidence from SIGE. Journal of Business Cycle Research, 13(1), 75-104. https://doi.org/10.1007/s41549-017-0015-8

D’Amato, L., Garegnani, L., \& Blanco, E. (2015). GDP Nowcasting: Assessing business cycle conditions in Argentina. BCRA Working Paper Series, 2015/69. Retrieved from https://www.bcra.gob.ar/Pdfs/Investigaciones/WP_69_2015\%20i.pdf on August, 01, 2020.

Darracq Paries, M., \& Maurin, L. (2008). The role of country-specific trade and survey data in forecasting euro area manufacturing production: perspective from large panel factor models. European Central Bank Working Paper, 894. Retrieved from https://ssrn.com/abstract=1120700 on August 1, 2020.

De Mol, C., Giannone, D., \& Reichlin, L. (2008). Forecasting using a large number of predictors: Is Bayesian shrinkage a valid alternative to principal components?. Journal of Econometrics, 146(2), 318-328.

Drechsel, K., \& Maurin, L. (2011). Flow of Conjuntural Information and Forecast of Euro Area Economic Activity. Journal of Forecasting, 30(3), 336-354. https://doi.org/10.1002/for.1177

Dubovskiy, D., Kofanov, D., \& Sosunov, K. (2015). Datirovka rossijskogo biznes-cikla [Dating of the Russian Business Cycle]. HSE Economic Journal, 19(4), 554-575. (In Russian).

European Commission (2014). What do survey data tell us about future price developments? (European Business Cycle Indicators - 2nd Quarter 2014, Publications Office of the European Union). Retrieved from https://ec.europa.eu/economy_finance/publications/cycle_indicators/2014/pdf/ebci_2_en.pdf on 23 July, 2020.

European Commission (2016). 'New Normal'? - The Impact of the Financial Crisis on Business and Consumer Survey Data (European Business Cycle Indicators - 3rd Quarter 2016, Publications Office of the European Union). https://doi.org/10.2765/600396

European Commission (2017). ESI and Other BCS Indicators vs PMI - Properties and Empirical Performance (European Business Cycle Indicators - 2nd Quarter 2017, Publications Office of the European Union). https://doi.org/10.2765/283995

European Commission (2018). Nowcasting euro area GDP growth with Mixed Frequency Models (European Business Cycle Indicators - 1st Quarter 2018, Publications Office of the European Union). https://doi.org/10.2765/17446

European Commission (2019). Recent Development in Survey Indicators (European Business Cycle Indicators 2nd Quarter 2019, Publications Office of the European Union). https://doi.org/10.2765/870948

European Commission (2020). The Joint Harmonised EU Programme of Business and Consumer Surveys. User Guide. Retrieved from https://ec.europa.eu/info/sites/info/files/bcs_user_guide_2020_02_en.pdf on August 20, 2020.

Fernandes, N. (2020). Economic Effects of Coronavirus Outbreak (COVID-19) on the World Economy. IESE Business School Working Paper, WP-1240-E. https://doi.org/10.2139/ssrn.3557504 
Galli, A., Hepenstrick, C., \& Scheufele, R. (2019). Mixed-Frequency Models for Tracking Short-Term Economic Developments in Switzerland. International Journal of Central Banking, 58, 151-178. Retrieved from https://www.ijcb.org/journal/ijcb19q2a5.htm on July 25, 2020.

Gayer, C. (2008). Report: The Economic Climate Tracer. A Tool to Visualise the Cyclical Stance of the Economy Using Survey Data (European Commission). Retrieved from http://ec.europa.eu/economy_finance/db_indicators/surveys/documents/studies/economic_climate_tracer_en.pdf on July 25, 2020.

Gayer, C., \& Marc, B. (2018). A 'New Modesty'? Level Shifts in Survey Data and the Decreasing Trend of 'Normal' Growth. (European Economy Discussion Paper, 083). https://doi.org/10.2765/067112

Giannone, D., Lenza, M., \& Primiceri, G.E. (2012). Prior Selection for Vector Autoregressions. ECB Working Paper Series, 1494. Retrieved from https://ssrn.com/abstract=2176133 on August 1, 2020.

Girardi, A. (2014). Expectations and macroeconomic fluctuations in the euro area. Economics Letters, 125(2), 315-318. https://doi.org/10.1016/j.econlet.2014.09.031

Girardi, A., Gayer, C., \& Reuter, A. (2015). The Role of Survey Data in Nowcasting Euro Area GDP Growth. Journal of Forecasting, 35(5), 400-418. Retrieved from https://ideas.repec.org/p/euf/ecopap/0538.html on July 25, 2020.

Gollier, C., \& Straub, S. (2020). The Economics of Coronavirus: Some Insights. Toulouse School of Economics: Public Policy. Retrieved from https://www.tse-fr.eu/economics-coronavirus-some-insights on November 20, 2020.

Granville, B., \& Mallick, S. (2010). Monetary Policy in Russia: Identifying exchange rate shocks. Economic Modelling, 27(1), 432-444. https://doi.org/10.1016/j.econmod.2009.10.010

Guerrieri, V., Lorenzoni, G., Straub, L., \& Werning, I. (2020). Macroeconomic Implications of COVID-19: Can Negative Supply Shocks Cause Demand Shortages?. NBER Working Paper, 26918. https://doi.org/10.3386/w26918

Hansson, J., Jansson, P., \& Löf, M. (2003). Business survey data: Do they help forecasting the macro economy (4th Eurostat and DG ECFIN colloquium on modern tools for business cycle analysis). Retrieved from https://ec.europa.eu/eurostat/documents/3888793/5828897/KS-AN-03-051-EN.PDF/aed6487a-48164846-9abb-f6cbfd98afd5 on July 24, 2020.

Hodrick, R.J., \& Prescott, E.C. (1997). Postwar U.S. Business Cycles: an Empirical Investigation. Journal of Money Credit and Banking, 29(1), 1-16. Retrieved from https://www.researchgate.net/publication/303087255_Post-war_US_business_cycles_An_empirical_investigation on July 24, 2020.

International Monetary Fund (2020). World Economic Outlook, October 2020: A Long and Difficult Ascent. Retrieved from https://www.imf.org/en/Publications/WEO/Issues/2020/09/30/world-economic-outlook-october-2020 on November 25, 2020.

Jorda, O., Singh, S.R., \& Taylor, A.M. (2020). Longer-Run Economic Consequences of Pandemics. NBER Working Paper, w26934. https://doi.org/10.3386/w26934

Kitrar, L., Lipkind, T., \& Ostapkovich, G. (2020). Information content of Russian services surveys. Journal of Business Cycle Research, 16(1), 59-74. https://doi.org/10.1007/s41549-020-00040-4

Kitrar, L., Lipkind, T., Lola, I., Ostapkovich, G., \& Chusovlyanov, D. (2015). The HSE ESI and Short-Term Cycles in the Russian Economy. Papers and Studies of Research Institute for Economic Development SGH, 97, 45-66.

Kitrar, L., \& Nilsson, R. (2003). Business Cycles and Cyclical Indicators in Russia. Paris: OECD.

Korhonen, I., \& Mehrotra, A. (2009). Real exchange rate, output and oil: Case of four large energy producers (BOFIT Discussion Paper, 6). https://doi.org/10.2139/ssrn.1428238

Korhonen, I., \& Mehrotra, A. (2010). Money demand in post-crisis Russia: de-dollarisation and remonetisation. Emerging Markets Finance and Trade, 46(2), 5-19. https://doi.org/10.2753/ree1540-496x460201

Lehmann, R., \& Wohlrabe, K. (2013). Forecasting GDP at the Regional Level with Many Predictors. CESifo Working Paper Series, 3956.

Lipkind, T., Kitrar, L., \& Ostapkovich, G. (2019). Russian Business Tendency Surveys by HSE and Rosstat. In S. Smirnov, A. Ozyildirim, \& P. Picchetti (Eds.), Business Cycles in BRICS (pp. 233-251). Springer.

Litterman, R. (1986). Forecasting with Bayesian vector autoregressive model - five years of experience. Journal of Business \& Economic Statistics, 4(1), 21-36.

Lütkepohl, H. (2011). Vector Autoregressive Models. In M. Lovric (Ed.) International Encyclopedia of Statistical Science. Berlin, Heidelberg: Springer. https://doi.org/10.1007/978-3-642-04898-2_609 
Mallick, S.K., \& Sousa, R.M. (2013). Commodity Prices, Inflationary Pressures, and Monetary Policy: Evidence from BRICS Economies. Open Economies Review, 24(4), 677-694. https://doi.org/10.1007/s11079-012-9261-5

Mattos, D., Sequeira, A.N., Lobão, W., \& Costa Ferreira, P. (2016). Forecasting Brazilian industrial production with the VAR model and SARIMA with smart dummy (Presentation at the CIRET conference, Copenhagen).

Mayr, J., \& Ulbricht, D. (2007). VAR Model Averaging for Multi-Step Forecasting. Ifo Working Paper, 48. Retrieved from https://www.ifo.de/DocDL/IfoWorkingPaper-48.pdf on August 14, 2020.

Mehrotra, A., \& Ponomarenko, A. (2010). Wealth effects and Russian money demand. BOFIT Discussion Paper Series, 13. Retrieved from https://doi.org/10.2139/ssrn.1665039 on August 1, 2020.

Nilsson, R., \& Gyomai, G. (2011). Cycle Extraction. A Comparison of the PAT Method, the Hodrick-Prescott and Christiano-Fitzgerald Filters. OECD Statistics Directorate Working Paper, 39. Retrieved from http://www.oecd.org/std/leading-indicators/41520591.pdf on July 28, 2020.

OECD (2012). OECD System of Composite Leading Indicators. Retrieved from http://www.oecd.org/sdd/leadingindicators/41629509.pdf on November 30, 2020.

Ollivaud, P., Pionnier, P-A., Rusticelli, E., Schwellnus, C., \& Seung-Hee, K. (2016). Forecasting GDP during and after the Great Recession: A contest between small-scale bridge and large-scale dynamic factor model. OECD ECOnomics Department Working paper 1313. Retrieved from https://www.oecd.org/officialdocuments/publicdisplaydocumentpdf/?cote=ECO/WKP(2016)37\&docLanguage=En on August 1, 2020.

Polbin, A. (2020). Ocenka traektorii tempov trendovogo rosta VVP Rossii v ARX-modeli s cenami na neft' [Estimating Time-Varying Long-Run Growth Rate of Russian GDP in the ARX Model with Oil Prices]. Ekonomicheskaya Politika [Economic Policy], 15(1), 40-63. https://doi.org: 10.18288/1994-5124-2020-1-40-63 (In Russian).

Rautava, J. (2013). Oil prices, Excess Uncertainty and Trend Growth: a Forecasting Model for Russia's Economy (Austrian Central Bank, Focus on European Economic Integration, 4, pp. 77-87). Retrieved from https://www.oenb.at/dam/jcr:aeee8d5b-ff32-4db7-919c-7e37e5d1fcb9/feei_2013_q4_studies_rautava.pdf on August 14, 2020.

Rayskaya, N., Sergienko, Ya., Frenkel, A., \& Matveeva, O. (2012). Indikator ekonomiki [Economy indicator]. Ekonomicheskie strategii [Economic Strategies], 9, 32-39 (in Russian).

Sinelnikov-Murylev, S., Drobyshevsky, S., Kazakova, M., \& Alexeev, M. (2015). Dekompoziciya tempov rosta VVP Rossii [Decomposition of Russia's GDP Growth Rates]. Gaidar Institute for Economic Policy. Nauchnye Trudy, 167 (in Russian).

Smirnov, S. (2020). Predskazanie povorotnykh tochek rossiyskogo ekonomicheskogo tsikla s pomoshch'yu svodnykh operezhayushchikh indeksov [Turning Points of the Russian Economic Cycle Using Composite Leading Indicators], Voprosy Statistiki, 27(4), 53-65. https://doi.org/10.34023/2313-6383-2020-27-4-53-65 (in Russian).

UNECE (2019). Guidelines on Producing Leading, Composite and Sentiment Indicators. Geneva: United Nations. 


\section{Authors}

Contribution share of authors is equal and amounted to $50 \%$ for each of them.

\section{Liudmila Kitrar}

Candidate of Sciences (PhD) in Mathematical and Instrumental Methods in Economics; Deputy Director of the Centre for Business Tendency Studies, Higher School of Economics, Moscow, Russian Federation; member of the Russian Association of Statisticians; UNIDO international expert. Her research interests include: indicator approach to measuring economic dynamics; methods of quantification, analysis, and visualisation of nonparametric statistics; econometric methods of decomposition of unobservable variables in economic dynamics; entrepreneurial expectations; VAR models and statistical filtering in the practice of business tendency monitoring.

Correspondence to: Dr. Liudmila Kitrar, National Research University Higher School of Economics, Institute for Statistical Studies and Economics of Knowledge, Centre for Business Tendency Studies, Slavyanskaya Sq., 4/2, Moscow, 101000, Russian Federation, e-mail: Ikitrar@hse.ru

ORCID (1) http://orcid.org/0000-0002-6383-9562

\section{Tamara Lipkind}

Leading expert of the Centre for Business Tendency Studies, Higher School of Economics, Moscow, Russian Federation. Her research interests include: composite indicators of business cycles; business and consumer surveys; sectoral and regional comparative analysis of economic sentiment and business climate; quantification and visualisation of nonparametric statistics.

Correspondence to: Tamara Lipkind, National Research University Higher School of Economics, Institute for Statistical Studies and Economics of Knowledge, Centre for Business Tendency Studies, Slavyanskaya Sq., 4/2, Moscow, 101000, Russian Federation, e-mail: tlipkind@hse.ru

ORCID (1) http://orcid.org/0000-0003-2632-9026

\section{Acknowledgements and Financial Disclosure}

The article was prepared within a framework of the Basic Research Program of the National Research University Higher School of Economics.

\section{Conflict of Interest}

The authors declare that the research was conducted in the absence of any commercial or financial relationships that could be construed as a potential conflict of interest.

\section{Copyright and License}

This article is published under the terms of the Creative Commons

Attribution - NoDerivs (CC BY-ND 4.0) License

http://creativecommons.org/licenses/by-nd/4.0/

Published by Cracow University of Economics - Krakow, Poland 
